\title{
Inoculação com Rhizobium tropici e adubação foliar com molibdênio na cultura do feijão comum
}

\author{
Carlos Alberto Bispo de Oliveira ${ }^{1}$, Gláucia de Mello Pelá ${ }^{2}$ Adilson Pelá \\ ${ }^{1}$ Instituto Federal Goiano, Campus de Urutaí, Urutaí, Goiás, Brasil. E-mail: caboliveira@ hotmail.com \\ ${ }^{2}$ Universidade Estadual de Goiás, Campus Ipameri, Ipameri, Goiás, Brasil. E-mail: glauciapela@gmail.com, adilson.pela@ueg.br
}

Recebido: 09/11/2017; Aceito:10/11/2017

\section{RESUMO}

O feijão comum, em simbiose com a rizobactéria Rhizobium tropici, é capaz de ter a sua exigência de nitrogênio (N) satisfeita com a fixação biológica de nitrogênio (FBN) que por sua vez é afetada pela deficiência de molibdênio (Mo) visto que este nutriente faz parte da enzima nitrogenase, responsável pelo processo. $\mathrm{O}$ objetivo deste trabalho foi avaliar a resposta do feijão comum e seus componentes: teor de clorofila, teor de nitrogênio, produtividade de grãos, número de vagens por planta, número de grãos por vagem, peso de mil sementes, matéria fresca da parte aérea (MFPA), matéria seca da parte aérea (MSPA), matéria fresca das raízes (MFR), matéria seca das raízes (MSR), e produção de biomassa da cultura ao uso da inoculação das sementes combinadas com a aplicação de diferentes doses de molibdênio (Mo) via foliar. O experimento foi conduzido na $2^{\mathrm{a}}$ safra, período de janeiro a abril de 2015, num Latossolo Vermelho distrófico, com textura média, em uma área experimental irrigada por pivô central no município de Urutaí-GO. O experimento foi conduzido em blocos casualizados, arranjados em esquema fatorial $2 \times 4$, com três repetições. O primeiro fator corresponde à inoculação ou não da rizobactéria da espécie Rhizobium tropici, e o segundo fator, às doses de Molibdênio aplicado via foliar $(0,50$, $100 \mathrm{e} 150 \mathrm{~g} \mathrm{ha}^{-1}$ ). A inoculação das sementes, associada à dose de $150 \mathrm{~g} \mathrm{ha}^{-1}$ promoveram aumentos significativos nos componentes de desenvolvimento e produtividade do feijão comum.

Palavras-chave: Phaseolus vulgaris L., fixação biológica do nitrogênio, teor de nitrogênio, nutrição de plantas.

\section{Inoculation with Rhizobium tropici and foliar fertilization with molibdenum in the common bean crop}

\begin{abstract}
The common bean, in symbiosis with Rhizobium tropici, can have its nitrogen exigence $(\mathrm{N})$ satisfied with a biological fixation of nitrogen (BFN). Therefore, BFN is affected by molybdenum deficiency (Mo), since this nutrient is part of nitrogenase enzyme, responsible for the process. The aim of this work was to evaluate the response of common bean crop and their components: chlorophyll proportion, grain yield, number of pods per plant, number of grains per pod, weigh of one thousand seeds, shoot fresh matter (SFM), shoot dry matter (SDM), root fresh matter (RFM), root dry matter (RDM), and biomass production of the crop as affected by use inoculation with Rhizobium tropici combined with the foliar application of different doses of molybdenum (Mo). The experiment was conducted in the $2^{\text {nd }}$ crop, January to April 2015 in a Latossolo Vermelho of Cerrado in an experimental area irrigated, in Urutai-GO. The experiment was led in randomized blocks, arranged in factorial scheme $2 \times 4$, with three replicates. The first factor corresponds to the inoculation or not of the Rhizobuim tropici, and the second factor, the doses of molybdenum applied via foliar $\left(0,50,100\right.$ and $\left.150 \mathrm{~g} \mathrm{ha}^{-1}\right)$. Seeds inoculation associated to the dose of $150 \mathrm{~g} \mathrm{ha}^{-1}$ promoted significant increases in the development components and grain yield of the common bean.
\end{abstract}

Key words: Phaseolus vulgaris L., biological fixation of nitrogen, nitrogen content, plant nutrition. 


\section{Introdução}

O feijão comum (Phaseolus vulgaris L.) é a espécie mais cultivada no mundo entre as demais do gênero Phaseolus, sendo o Brasil o maior produtor e consumidor (DEPEC, 2017). O desenvolvimento de tecnologias proporcionou o cultivo em uma grande diversidade de sistemas de produção, com rendimento de grãos entre 3.000 e $4.000 \mathrm{~kg} \mathrm{ha}^{-1}$. Tem sido cultivado em todas as regiões do país apresentando grande importância econômica e social. O feijão possui características que tornam seu consumo vantajoso do ponto de vista nutricional. Entre eles citam-se o conteúdo proteico, o teor elevado de lisina, fibra alimentar, alto conteúdo de carboidratos complexos e a presença de vitaminas do complexo B (SANTOS; SILVA, 2003).

Segundo a companhia nacional de abastecimento, (CONAB, 2014), o Brasil é um dos maiores produtores mundiais de feijão, no entanto, o rendimento médio da cultura ainda é muito baixo. Entre as razões do baixo rendimento está a indisponibilidade ou inacessibilidade de tecnologia de plantio e manejo adaptada aos pequeno e médio produtores, pois o feijoeiro ainda é, em boa parte, uma cultura de subsistência. A utilização inadequada de fertilizantes, especialmente o nitrogênio, também exerce influência determinante na produtividade da cultura.

Os fertilizantes nitrogenados, além do custo elevado, podem contribuir para a poluição ambiental. $\mathrm{O} \mathrm{N}_{2}$, que constitui $80 \%$ da atmosfera, possui forte ligação entre os átomos de $\mathrm{N}$, não sendo quebrada por nenhuma planta, mas apenas por algumas bactérias, incluindo os rizóbios que formam associações simbióticas com plantas leguminosas segundo Pessoa et al. (2000). Neste sentido, a utilização de insumos biológicos em substituição aos insumos químicos industrializados tem sido cada vez mais frequente na agricultura. A fixação biológica de nitrogênio (FBN) tem se mostrado indispensável para a sustentabilidade da agricultura brasileira, haja vista o fornecimento de nitrogênio às culturas com baixo custo econômico e impacto ambiental reduzido (HUNGRIA et al., 2007).

As bactérias do grupo Rhizobium são capazes de fixar o nitrogênio atmosférico e fornecê-lo à planta. Essa interação representa uma simbiose, ou mais especificamente, uma interação mutualística, a partir do momento em que a bactéria se beneficia do suprimento de fotossintatos ou carbono orgânico fornecidos pela planta hospedeira. Enquanto a planta recebe o nitrogênio fixado pelo rizóbio microssimbionte na forma amoniacal, assimilando-o em compostos nitrogenados que podem ser translocados para suas diferentes partes (CASSINI; FRANCO, 2011).

O feijoeiro desenvolve associação simbiótica nas raízes com a bactéria Rhizobium tropici, quando esta bactéria está presente no solo, naturalmente ou via inoculação, ela reconhece e infecta as raízes da planta hospedeira, provocando a formação de nódulos onde ocorre a fixação do $\mathrm{N}_{2}$. Após a iniciação do nódulo, o Rhizobium transforma-se em bacteroide que se multiplica e começa a sintetizar a nitrogenase, a enzima responsável pela redução no $\mathrm{N}_{2}$ iniciando-se a fixação (HUNGRIA et al., 2007). Para que uma estirpe (ou estirpes) de Rhizobium possa ser recomendada para inoculação do feijão, é preciso que possua, dentre outros atributos, eficiência na fixação de $\mathrm{N}_{2}$ e características de competição com os microrganismos ali presentes.

A importância do molibdênio no processo de fixação biológica de nitrogênio (FBN) foi primeiramente descrita por Bortels (1930), que demonstrou que Azotobacter vinelandii, quando inoculado em meio de cultura sem $\mathrm{N}$ combinado, necessitava de Mo para crescer, o que não ocorria se a fonte de $\mathrm{N}$ do meio de cultura fosse o amônio. Posteriormente, Bulen e Lecontee (1966), demonstraram que a nitrogenase purificada continha Mo. Sabe-se que o Molibdênio faz parte do co-fator ferro-molibdênio, o grupo prostético da fração da nitrogenase do complexo enzimático nitrogenase (MARTENS; WESTERMANN, 1991).

Por participar da estrutura e ser ativador de diversas enzimas, o Mo é de fundamental importância a todos os vegetais. Essa importância aumenta no caso do feijão, que tem a capacidade de estabelecer simbiose com microrganismos fixadores de $\mathrm{N}_{2}$ pertencentes à família Rhizobiaceae. Esses microrganismos infectam as raízes do feijoeiro e formam os nódulos, em cujo interior é sintetizado um complexo enzimático, denominado nitrogenase, que rompe a tripla ligação existente entre os átomos de $\mathrm{N}$ que formam a molécula do $\mathrm{N}_{2}$ e utilizam esses átomos para produzir duas moléculas de amônia $\left(\mathrm{NH}_{3}\right)$, que são fornecidas à planta, para sintetizar os compostos nitrogenados. A leguminosa, em contrapartida, fornece carboidratos aos microrganismos (ALBINO; CAMPO, 2001).

O suprimento de Mo é feito predominantemente na forma de molibdato $\left(\mathrm{MoO}_{4}^{-2}\right)$ presente na solução do solo, que chega às raízes via fluxo de massa pelo xilema e floema (MESCHEDE et al., 2004). Devido à alta mobilidade do molibdênio na planta, a adubação foliar pode proporcionar bons resultados, desde que seja realizada no início do período do desenvolvimento vegetativo da cultura.

Estudos à campo têm demonstrado incrementos no rendimento de grãos na cultura do feijoeiro, pela inoculação com estirpes de rizóbio de elevada eficiência simbiótica e competitividade, em relação à população nativa de rizóbio do solo (PERES et al., 1994; HUNGRIA et al., 2007).

Neste contexto se destaca a necessidade do desenvolvimento de tecnologias eficientes e de baixo 
custo econômico e ambiental capazes de elevar os níveis de produtividade da cultura. Há indicativos de que alguns fatores podem aumentar a eficiência da FBN no feijoeiro destacando-se o uso da adubação molíbdica (ALBUQUERQUE et al., 2012) uma vez que o Mo, sendo constituinte básico das enzimas nitrogenase e redutase do nitrato, está diretamente envolvido no metabolismo do $\mathrm{N}$ promovendo seu aproveitamento na forma nítrica (redutase do nitrato) ou atmosférica (nitrogenase) (PESSOA et al., 2001).

Assim considera- se a hipótese de que a adubação química nitrogenada, comumente utilizada, poderia ser substituída parcial ou totalmente, pela adubação química foliar de molibdênio associado ao uso de inoculante. $\mathrm{O}$ objetivo desse trabalho foi avaliar o possível efeito no feijão comum à inoculação das sementes com Rhizobium tropici, combinadas com aplicação de doses de molibdênio (Mo) via foliar em seus componentes de produção e produtividade.

\section{Material e Métodos}

O experimento foi conduzido na $2^{a}$ safra, ou seja, no período de janeiro a abril de 2015, num Latossolo Vermelho Distrófico, com textura média, em uma área experimental irrigada por pivô central, sistema de plantio direto em palhada de milho, no Instituto Federal Goiano - Câmpus de Urutaí - GO (17³0'53', S; 48 12 '22” W, $731 \mathrm{~m}$ ). O clima, segundo a classificação de Koppen, é do tipo Cwa, ou seja, mesotérmico de inverno seco, médias de temperaturas mensais superiores a $25^{\circ} \mathrm{C}$, índice pluviométrico variando de 1100 a $1800 \mathrm{~mm}$ anuais.

De acordo com a análise química do solo obtida por amostragem antes da instalação do experimento para sua caracterização e as análises realizadas no laboratório de fertilidade de solo e nutrição de plantas do Campus Urutaí-GO, não foi utilizado calcário devido à boa saturação por bases apresentada na área. Seguem os resultados das análises: na profundidade de $0-20 \mathrm{~cm}$ obteve-se: $\mathrm{pH} \mathrm{H}_{2} \mathrm{O}(1: 1,25)$ 6,5; P - Mehlich-1 48,3 mg

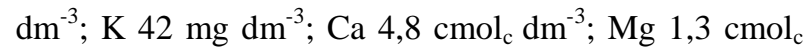
$\mathrm{dm}^{-3} ; \mathrm{Al} \mathrm{0,0} \mathrm{cmol}_{\mathrm{c}} \mathrm{dm}^{-3} ; \mathrm{H}+\mathrm{Al} 2,2 \mathrm{cmol}_{\mathrm{c}} \mathrm{dm}^{-3} ; \mathrm{Cu} 2,4$ $\mathrm{mg} \mathrm{dm}^{-3}$; Fe $51 \mathrm{mg} \mathrm{dm}^{-3}$; Mn 6,9 $\mathrm{mg} \mathrm{dm}^{-3}$; Zn 0,8 mg $\mathrm{dm}^{-3}$; M.O. 1,8 dag kg $\mathrm{kg}^{-1}$ CTC a pH 7,0 - 12,5; soma de bases 10,3 e V\% 82,4. Na profundidade de 20-40 cm foram determinados: $\mathrm{pH} \mathrm{H}_{2} \mathrm{O}(1: 1,25) 6,5 ; \mathrm{P}$ - Mehlich1 49,2 $\mathrm{mg} \mathrm{dm}^{-3}$; K $24 \mathrm{mg} \mathrm{dm}{ }^{-3}$; Ca 3,4 $\mathrm{cmol}_{\mathrm{c}} \mathrm{dm}^{-3} ; \mathrm{Mg}$ $0,9 \mathrm{cmol}_{\mathrm{c}} \mathrm{dm}^{-3} ; \mathrm{Al} 0,0 \mathrm{cmol}_{\mathrm{c}} \mathrm{dm}^{-3} ; \mathrm{H}+\mathrm{Al} \mathrm{2,0} \mathrm{cmol}_{\mathrm{c}} \mathrm{dm}^{-3}$; $\mathrm{Cu} 1,2 \mathrm{mg} \mathrm{dm}^{-3}$; Fe $23 \mathrm{mg} \mathrm{dm}^{-3}$; Mn 3,9 $\mathrm{mg} \mathrm{dm}^{-3} ; \mathrm{Zn}$ 1,9 mg dm${ }^{-3}$; M.O. $1,3 \mathrm{dag} \mathrm{kg}^{-1}$; CTC a $\mathrm{pH} \mathrm{7,0} \mathrm{-} \mathrm{8,7;}$ soma de bases 6,7 e V\% 77,0.

$\mathrm{O}$ experimento foi conduzido em blocos casualizados, arranjados em esquema fatorial $2 \times 4$, com três repetições. Os tratamentos foram estabelecidos com o primeiro fator corresponde à inoculação ou não das sementes de feijão cv. 'Pérola' a rizobactéria Rhizobium tropici (NITRO $1000^{\circledR}$, Cascavel-PR, estirpes SEMIA 4077 e SEMIA 4088, na concentração de 1 x $10^{9}$ rizóbios por grama, com dose de 100 gramas $/ 50 \mathrm{~kg}$ sementes), e o segundo fator, as doses de molibdênio aplicadas via foliar com as seguintes doses: 0, 50, $100 \mathrm{e}$ $150 \mathrm{~g} \mathrm{ha}^{-1}$, totalizando 24 parcelas com 5 linhas de plantio com 4 metros de comprimento, com área útil de cada parcela de $10 \mathrm{~m}^{2}(0,5 \mathrm{~m}$ entre linhas e 12 sementes por metro linear). Sendo os tratamentos: T1- sem inoculação e sem Mo (controle); T2 - sem inoculação + $50 \mathrm{~g} \mathrm{ha}^{-1}$ de Mo; T3 - sem inoculação + $100 \mathrm{~g} \mathrm{ha}^{-1} \mathrm{de}$ Mo; T4 - sem inoculação + $150 \mathrm{~g} \mathrm{ha}^{-1}$ de Molibdênio; T5 - com inoculação e sem Mo; T6- com inoculação + $50 \mathrm{~g} \mathrm{ha}^{-1}$ de Mo; T7 - com inoculação + $100 \mathrm{~g} \mathrm{ha}^{-1} \mathrm{de}$ Mo; T8 - com inoculação $+150 \mathrm{~g} \mathrm{ha}^{-1}$. Foi realizada a dessecação da área utilizando o herbicida Glifosato na concentração - 360 a 720 g do ingrediente ativo por litro, na dose de 2,5 $\mathrm{L} \mathrm{ha}^{-1}$ a 30 dias antes do plantio.

$\mathrm{Na}$ adubação de plantio foi utilizado, segundo a recomendação da análise química do solo: $120 \mathrm{~kg} \mathrm{ha}^{-1}$ de $\mathrm{P}_{2} \mathrm{O}_{5}$ e $90 \mathrm{~kg} \mathrm{ha}^{-1}$ de $\mathrm{K}_{2} \mathrm{O}$. Não foi aplicado $\mathrm{N}$ na adubação de plantio nem em cobertura, para garantir que o nitrogênio fixado fosse exclusivamente através da fixação biológica. Para o preparo do inoculante foi colocado em um becker, $20 \mathrm{~mL}$ de água e adicionado 5 gramas do inoculante, mexendo até obter uma suspensão homogênea, essa calda foi suficiente para inocular $2,5 \mathrm{~kg}$ de sementes, a calda foi aplicada diretamente sobre as sementes e misturada até apresentar uma cobertura uniforme.

A fonte de molibdênio utilizada foi o molibdato de amônio $\left(\left(\mathrm{NH}_{4}\right) 6 \mathrm{Mo}_{7} \mathrm{O}_{24} \cdot 4 \mathrm{H}_{2} \mathrm{O}\right)$ a $54,3 \%$, preparando a solução utilizando água destilada, aplicado via foliar dividido em duas aplicações, uma 30 DAE, quando a planta apresentava o terceiro trifólio, e a outra $50 \mathrm{DAE}$, no início da floração, com uma calda de 200 L por hectare na primeira aplicação e $400 \mathrm{~L}$ para a segunda aplicação, devido ao aumento da área foliar com o crescimento das plantas. Foi utilizado um pulverizador manual costal de 20 litros, com o bico do tipo cone.

$\mathrm{O}$ experimento foi conduzido no período chuvoso e quando necessário foi aplicado uma lâmina média de irrigação de $10 \mathrm{~mm}$ no início até o estabelecimento da cultura. Para a avaliação do teor nitrogênio nas folhas, foram coletadas 50 folhas com pecíolo, no terço médio das plantas, colhidas aleatoriamente no período de florescimento aos 15 dias após a segunda aplicação de molibdênio; as folhas foram submetidas a uma lavagem rápida com água destilada e colocadas para secarem em estufa com circulação forçada de ar a temperatura de 65 ${ }^{\circ} \mathrm{C}$, por 72 horas, logo após moídas no moinho, com peneira de 30 mesh. Em seguida, determinado o teor de N conforme método Kjeldahl (SILVA, 2009a). 
Para determinar o peso da massa fresca parte aérea e raízes, no final do ciclo de enchimento dos grãos foram coletadas 10 plantas aleatoriamente dentro da área útil da parcela, feita a lavagem das raízes retirado o excesso de água, posteriormente feito o corte no colo caulinar, separando a parte aérea da raiz. Para determinar o peso de massa seca (parte aérea e raízes), as plantas que foram utilizadas para determinação da massa fresca, foram acondicionadas em sacos de papel, secas em estufa com ventilação forçada (BOD) à temperatura de $65^{\circ} \mathrm{C}$, até atingir o peso constante.

Para avaliação dos componentes de produção e rendimento, na ocasião da colheita coletou-se 10 plantas em local pré-determinado na área útil de cada parcela e deixadas para secagem a pleno sol. Após a secagem, submeteu-se a trilhagem mecânica, sendo os grãos pesados e os dados corrigidos a $13 \%$ de umidade e transformados em $\mathrm{kg} \mathrm{ha}^{-1}$. Em seguida foi contado mil grãos, e posteriormente pesado em balança de precisão. Para a avaliação do número de vagens/planta, número de grãos/vagem, foi feito arranquio de 10 plantas colhidas na parcela e realizada a contagem das vagens e depois o número de grãos por vagem. Para a variável acúmulo de biomassa por ocasião da colheita (ramos, folhas, vagens e raízes), foram colhidas três linhas em $1,0 \mathrm{~m}^{2}$, ou seja, 30 plantas no total, essas plantas foram pesadas, seu peso dividido pela área colhida convertidos os valores para $\mathrm{kg} \mathrm{m}^{-2}$.

Os dados foram submetidos à análise de variância (teste F) e as médias comparadas pelo teste de Tukey a
$1 \%$ de significância para efeito da inoculação, e para as doses de molibdênio foram realizadas análise de regressão. As análises estatísticas foram realizadas com o programa SISVAR 5.3 (FERREIRA, 2011).

\section{Resultados e Discussão}

Na Tabela 1 estão apresentados teor de $\mathrm{N}$ nas folhas, massa fresca da parte aérea (MFPA), massa seca da parte aérea (MSPA), número de vagens por planta, massa fresca da raiz (MFR), massa seca da raiz (MSR), acúmulo de biomassa, peso de 1000 grãos e produtividade de grãos de acordo com a inoculação e doses de aplicação de molibdênio no feijoeiro.

$\mathrm{O}$ uso do inoculante proporcionou maior teor de clorofila, $\mathrm{N}$ foliar, MFPA, número de vagens por planta, biomassa de parte aérea, peso de 1000 grãos e produtividade da cultura. Os desdobramentos das interações entre a inoculação e as doses de molibdênio, apresentaram comportamentos semelhantes para todas as variáveis analisadas exceto para a massa fresca e massa seca da raiz.

Quanto ao teor de nitrogênio, houve um acréscimo significativo (Figura 1a), principalmente associado à inoculação, da mesma forma como ocorreu com o teor de clorofila. Pessoa et al. (2000) também verificaram maiores teores de $\mathrm{N}$ total e $\mathrm{N}$ orgânico nas folhas do feijoeiro em função da aplicação de Mo via foliar, o que indica efeito positivo do micronutriente no aproveitamento do $\mathrm{N}$ absorvido pela planta.

Tabela 1. Teores de nitrogênio nas folhas, MFPA- massa seca da Parte aérea, MSPA- massa seca da parte aérea, número de vagem por planta, MFR- massa fresca da raiz, MSR - massa seca da raiz, acúmulo de biomassa, peso de 1000 grãos e produtividade (Prod).

\begin{tabular}{|c|c|c|c|c|c|c|c|c|c|}
\hline & Teor de $\mathrm{N}$ & MFPA & MSPA & $\mathrm{N}^{\circ}$ Vagem & MFR & MSR & Biomassa & Peso 1000 & Prod \\
\hline & $\mathrm{g} \mathrm{kg}^{-1}$ & $\mathrm{~kg} \mathrm{pl}^{-1}$ & & $\mathrm{pl}$ & $\mathrm{kg} \mathrm{pl}^{-1}$ & $\mathrm{~kg} \mathrm{pl}^{-1}$ & $\mathrm{~kg} \mathrm{~m}^{2}$ & g & $\mathrm{kg} \mathrm{ha}^{-1}$ \\
\hline \multicolumn{10}{|c|}{ Inoculante (Fator A) } \\
\hline Sem & $30,66 b$ & $0,13 b$ & $0,03 b$ & $5,16 b$ & $0,97 \mathrm{a}$ & $0,22 a$ & $1,41 \mathrm{~b}$ & $194,15 b$ & $691,05 b$ \\
\hline Com & $34,70 \mathrm{a}$ & $0,14 \mathrm{a}$ & $0,04 \mathrm{a}$ & $15,95 \mathrm{a}$ & $0,84 b$ & $0,22 \mathrm{a}$ & $1,53 \mathrm{a}$ & $212,51 \mathrm{a}$ & $2782,97 a$ \\
\hline $\mathrm{F}(\mathrm{A})$ & $306,83^{* *}$ & $67622 * *$ & $271499 * *$ & $11430 * *$ & $28504 * *$ & $0,09 \mathrm{~ns}$ & $56498 * *$ & $392073 * *$ & $45830 * *$ \\
\hline $\operatorname{Pr}>\mathrm{Fc}$ & $<0,001$ & $<0,001$ & $<0,001$ & $<0,001$ & $<0,001$ & $<0,76$ & $<0,001$ & $<0,0001$ & $<0,0001$ \\
\hline $\mathrm{dms}$ & 1,030 & 0,007 & 0,002 & 0,432 & 0,103 & 0,050 & 0,060 & 3,970 & 41,910 \\
\hline \multicolumn{10}{|c|}{ Molibdênio (Fator B) } \\
\hline Testemunha & $29,8 \mathrm{c}$ & $0,15 b$ & $0,038 b$ & $8,26 \mathrm{~d}$ & $0,79 \mathrm{~d}$ & $0,24 a$ & $1,59 \mathrm{a}$ & $197,72 \mathrm{c}$ & $1299,53 d$ \\
\hline $50 \mathrm{~g} \mathrm{ha}^{-1}$ & $31,10 \mathrm{c}$ & $0,11 \mathrm{~d}$ & $0,032 d$ & $8,93 \mathrm{c}$ & $0,94 b$ & $0,23 \mathrm{a}$ & $1,25 \mathrm{~d}$ & $131,66 \mathrm{~d}$ & $1355,32 \mathrm{c}$ \\
\hline $100 \mathrm{~g} \mathrm{ha}^{-1}$ & $32,85 b$ & $0,12 \mathrm{c}$ & $0,035 \mathrm{c}$ & $10,36 b$ & $1,08 \mathrm{a}$ & $0,22 \mathrm{a}$ & $1,3 \mathrm{c}$ & $205,54 b$ & $1748,76 b$ \\
\hline $150 \mathrm{~g} \mathrm{ha}^{-1}$ & $37,25 \mathrm{a}$ & $0,16 \mathrm{a}$ & $0,045 \mathrm{a}$ & $14,83 \mathrm{a}$ & $0,88 \mathrm{c}$ & $0,20 \mathrm{a}$ & $1,74 \mathrm{a}$ & $212,58 \mathrm{a}$ & $2544,43 a$ \\
\hline $\mathrm{F}(\mathrm{B})$ & $283,13 * *$ & $212412 * *$ & $96708 * *$ & $816105^{* *}$ & $14425 * *$ & $1075 \mathrm{~ns}$ & 198166 & $60407 * *$ & $3453 * *$ \\
\hline $\mathrm{Pr}>\mathrm{Fc}$ & $<0,001$ & $<0,001$ & $<0,001$ & $<0,001$ & $<0,001$ & $<0,39$ & $<0,001$ & $<0,001$ & $<0,001$ \\
\hline $\mathrm{dms}$ & 1,630 & 0,009 & 0,003 & 0,586 & 0,140 & 0,790 & 0,090 & 5,390 & 56,820 \\
\hline $\mathrm{F}(\mathrm{A} X \mathrm{~B})$ & $18,16^{* *}$ & $127139 * *$ & $21708 * *$ & $61696 * *$ & $140742 * *$ & 17531 & $165961 * *$ & $18337 * *$ & $640960 * *$ \\
\hline $\operatorname{Pr}>\mathrm{Fc}$ & $<0,001$ & $<0,001$ & $<0,001$ & $<0,001$ & $<0,001$ & $>0,001$ & $<0,001$ & $<0,001$ & $<0,001$ \\
\hline $\mathrm{CV} \%$ & 2,13 & 0,28 & 0,38 & 2,34 & 6,54 & 14,81 & 2,69 & 1,12 & 1,38 \\
\hline
\end{tabular}

Médias seguidas de letra distintas na coluna diferem entre si pelo teste de Tukey $(\mathrm{P}<0,01)$. ** significativo a $1 \%$, pelo teste de Tukey, ns - não significativo pelo teste de Tukey. 
Oliveira et al. (1996) com aplicação de molibdênio em plantas de feijão, obtiveram maior número de vagens, maior teor de nitrogênio nas folhas e maior produção de grãos. O efeito das doses de Mo é explicado pelo fato deste elemento ser constituinte das enzimas nitrogenase, responsável pela conversão do nitrogênio atmosférico em amônia, e da nitrato redutase, que atua na assimilação do $\mathrm{N}$, essencialmente na redução do nitrato a nitrito (KUBOTA et al., 2008).

$\mathrm{O}$ maior acúmulo de $\mathrm{N}$ na parte aérea, pode ser justificável pelo aumento na eficiência da FBN tanto na inoculação quanto pela aplicação de Mo foliar. Para Epstein e Bloom (2006), o nutriente mais diretamente relacionado ao aumento da biomassa vegetal é o $\mathrm{N}$, desta forma, uma FBN eficiente disponibiliza mais $\mathrm{N}$ para as plantas aumentando a biomassa vegetal, conforme observado por Souza et al., (2008), para soja, e Xavier et al., (2008) para feijão-caupi. De forma oposta, houve acréscimo desse acúmulo de biomassa (Figura 1b) apenas no tratamento sem inoculação, enquanto que no tratamento com inoculação houve decréscimo, talvez devido à alocação do nitrogênio para a produtividade de grãos. O N é o nutriente absorvido em maiores quantidades pelo feijoeiro, sendo que aproximadamente $50 \%$ do $\mathrm{N}$ total absorvido é exportado para os grãos, a sua deficiência é a mais frequente (SORATTO et al., 2006).

Quanto ao número de vagens por planta, houve efeito linear crescente em razão da aplicação de Mo em ambos os tratamentos com e sem inoculação (Figura 2a). A inoculação de rizobactéria favoreceu um número superior de vagem por planta, em função da maior absorção de N. Para ambos os casos (com e sem inoculação de rizobactéria), resultados semelhantes foram encontrados por Andrade et al. (1998) que observaram aumento no número de vagens por planta com a aplicação do Mo via foliar no feijoeiro, em que a aplicação de $75 \mathrm{~g} \mathrm{ha}^{-1}$ de Mo via foliar promoveu maior acúmulo de matéria seca nas hastes + ramos, folhas, vagens e grãos do feijoeiro, o que resultou em acréscimo no rendimento de grãos, número de vagens/planta, número de grãos/vagem e peso médio de 100 grãos. Ascoli et al. (2008) observaram que os componentes da produção (número de vagens por planta, de sementes por vagem e massa de 100 sementes) não foram afetados pelos tratamentos com doses crescentes de Mo.
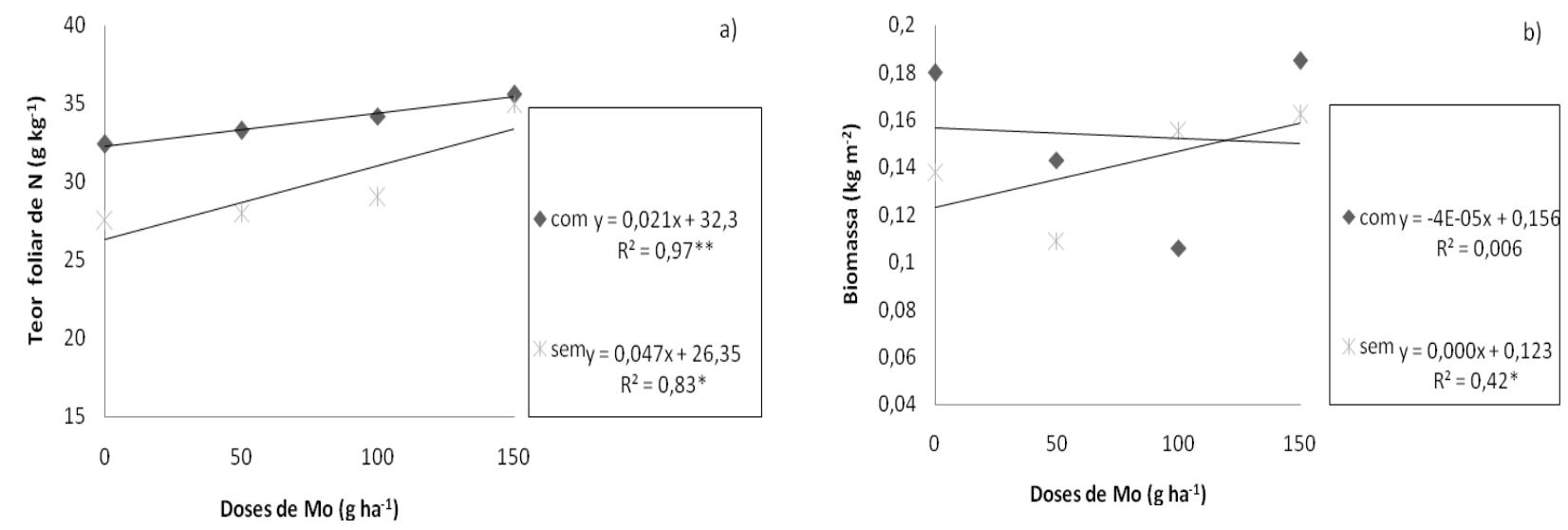

Figura 1. Teor de nitrogênio, nas folhas de feijoeiro, aos 45 DAE (a), em função da dose de molibdênio. Acúmulo de biomassa, em função das doses de molibdênio (b), com ou sem inoculação com $R$. tropici. * e ** = significativo a $5 \%$ e $1 \%$ de probabilidade.
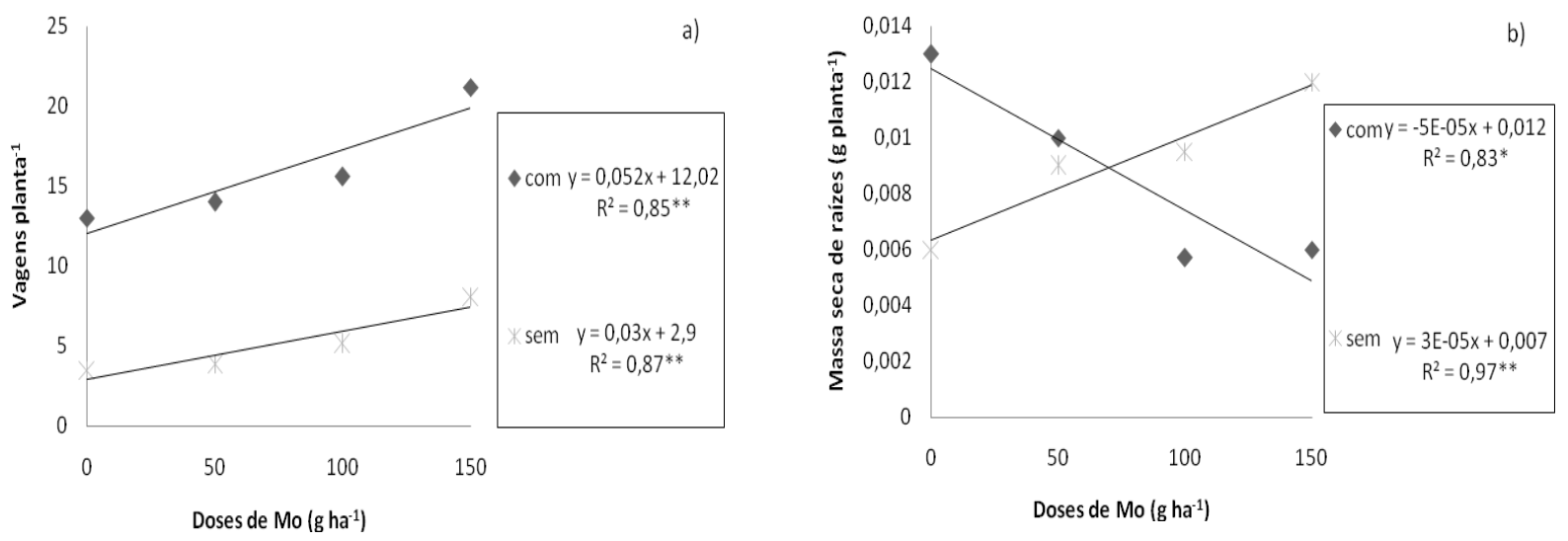

Figura 2. Número de vagem por planta, em função da dose de Molibdênio (a). Massa seca das raízes, em função da dose de molibdênio (b), com ou sem inoculação com $R$. tropici. ** = significativo a 5\% e $1 \%$ de probabilidade. 
O número de grãos por vagem não diferiu em função da inoculação e das doses de Mo aplicadas via foliar, provavelmente por se tratar de uma característica de alta herdabilidade genética, dependente de cada cultivar (TORRES et al., 2014). O número de sementes por vagem normalmente é uma característica varietal pouco influenciada pelo ambiente ou por práticas culturais adotadas (ARF et al., 2004). Resultados diferentes foram encontrados por Andrade et al. (2001) utilizando a cultivar Carioca-MG cultivada num Latossolo Vermelho Escuro distrófico observaram aumento no número de grãos por vagem com aplicação foliar de Mo.

A MFR não foi influenciada pela inoculação, mas para MSR as doses de molibdênio promoveram um aumento da massa das raízes no tratamento sem inoculação, e um decréscimo quando inoculado (Figura 2b). Resultados semelhantes foram encontrados por outros autores (GRIS et al., 2005; MARCONDES; CAIRES, 2005) em experimentos com doses crescentes de Mo em Latossolo Vermelho com pH (em água) de 5,0. As doses de Mo, associadas à inoculação, podem ter contribuído com maior fixação simbiótica de $\mathrm{N}$, reduzindo a necessidade da planta em investir na produção de raízes para aumentar a eficiência de absorção do $\mathrm{N}$ do solo, fato sustentado pelo comportamento inverso de variáveis como MFPA; MSPA, massa de 1000 grãos e produtividade.

Em contrapartida a MFPA e a MSPA (Figuras 3a e 3b) apresentaram resultados positivos quando tratados com inoculante e também para as doses de Mo. Isso porque a nitrogenase, enzima sintetizado pelos Rhizobium e responsável pela fixação do $\mathrm{N}_{2}$ (HUNGRIA et al., 2007) depende de Mo. O aumento na eficiência da FBN favorece o crescimento vegetativo (EPSTEIN; BLOOM, 2006). Estes resultados divergem dos obtidos por Souza et al. (2011), que não encontraram resposta à inoculação com $R$. tropici. Resultados semelhantes foram encontrados por Silva et al. (2009b) com a inoculação de rizóbio associada à adição de exsudado de sementes de Mimosa flocculosa,
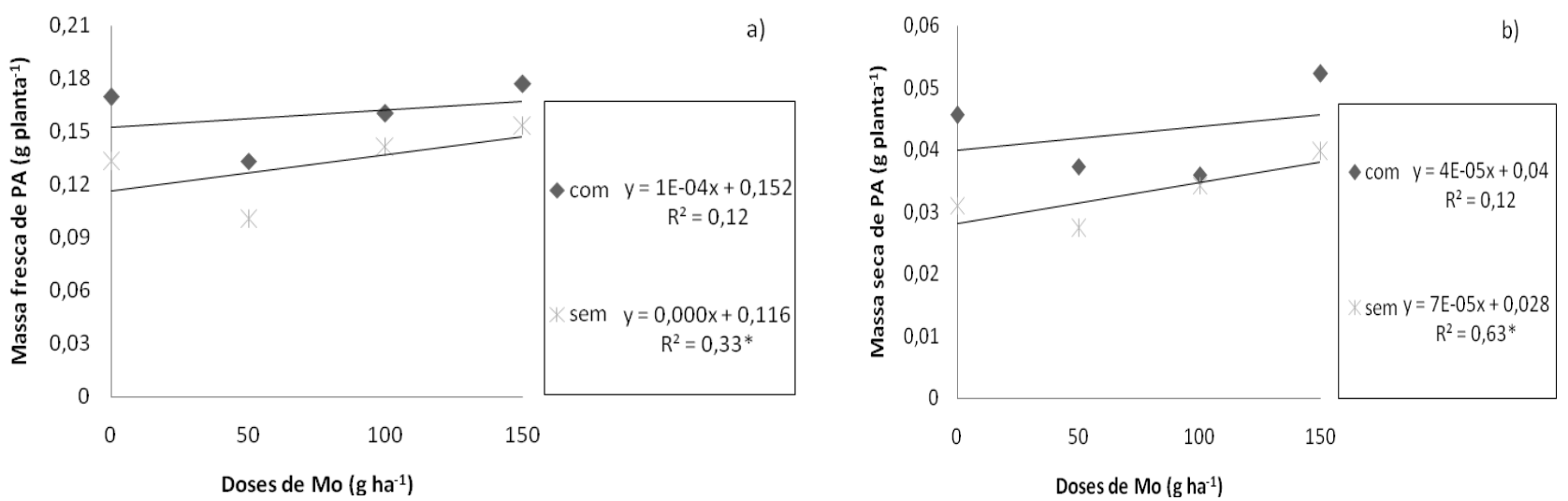

Figura 3. Massa fresca (a) e Massa fresca (b) da parte aérea (PA) em função das doses de molibdênio, com ou sem inoculação com R. tropici. $^{*}=$ significativo a $5 \%$ de probabilidade. 

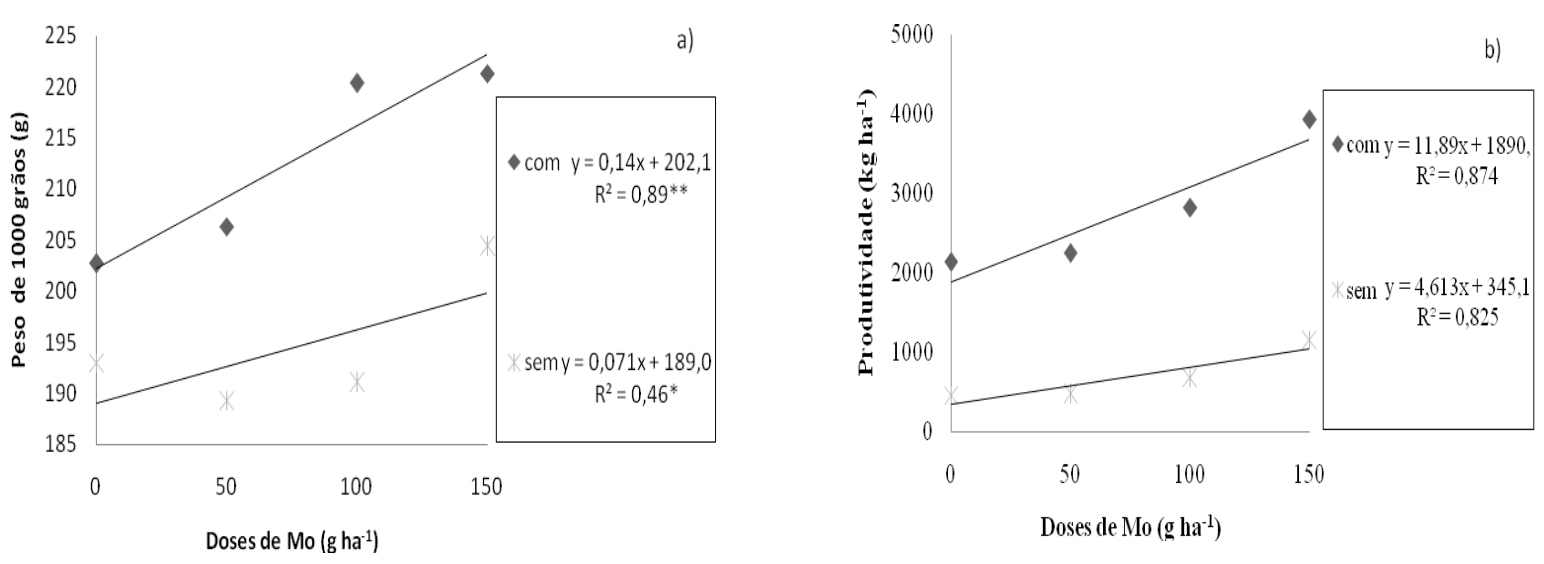

Figura 4. Peso de 1000 grãos (a) e produtividade de grãos (b), em função da dose de Molibdênio, com ou sem inoculação com $R$. tropici. $*$ e $* *=$ significativo a $5 \%$ e $1 \%$ de probabilidade.

\section{Conclusões}

A inoculação com $R$. tropici aumentou o teor de nitrogênio nas folhas, acúmulo de biomassa vegetal, número de vagem por planta, peso de 1000 grãos e a produtividade do feijão comum cv. Pérola.

A adubação nitrogenada na cultura do feijoeiro pode ser substituída na sua totalidade pela inoculação com a bactéria $R$. tropici, e pela adubação foliar com molibdênio.

\section{Referências Bibliográficas}

ALBINO, U. B.; CAMPO, R.J. Efeitos de fontes de molibdênio na sobrevivência do Bradyrhizibium e na fixação biológica de nitrogênio em soja. Pesquisa Agropecuária Brasileira, Brasília-DF, v. 36, n. 3, p. 527-534, 2001.

ALBUQUERQUE, H. C.; PEGORARO, R. F.; VIEIRA, N. M. B.; AMORIM, I. J. F.; KONDO, M. K. Capacidade nodulatória e características agronômicas de feijoeiros comuns submetidos à adubação molíbdica parcelada e nitrogenada. Revista Ciência Agronômica, Fortaleza-CE, v. 43, n. 2, p. 214-221, 2012.

ANDRADE, M. J. B.; DINIZ, A. R.; CARVALHO, J. G.; LIMA, S. F. Resposta da cultura do feijoeiro à aplicação foliar de molibdênio e às adubações nitrogenadas de plantio e cobertura. Ciência e Agrotecnologia, Lavras-MG, v. 22, n. 2, p.499-508, 1998.

ANDRADE, M. J. B.; ALVARENGA, P. E.; SILVA, R.; CARVALHO, J. G.; JUNQUEIRA, A. D. de A. Resposta do feijoeiro às adubações nitrogenada e molíbdica e à inoculação com Rhizobium tropici. Ciência e Agrotecnologia, LavrasMG, v.2 5, n. 4, p. 934-940, 2001.

ARF, O.; RODRIGUES, R. A. F.; SÁ, M. E.; BUZETTI, S.; NASCIMENTO, V. Manejo do solo, água e nitrogênio no cultivo de feijão. Pesquisa Agropecuária Brasileira. Brasília-DF, v. 39, n. 2, p. 131-138, 2004.

ASCOLI, A. A.; SORATTO, R. P.; MARUYAMA, W. I. aplicação foliar de molibdênio, produtividade e qualidade fisiológica de sementes de feijoeiro irrigado. Bragantia, Campinas-SP, v. 67, n. 2, p. 377-384, 2008
BASSAN, D. A. Z; ARF, O.; BUZETTI, S.; CARVALHO, M. A. C.; SANTOS, N. C. B.; E SÁ, M. E. Inoculação de sementes e aplicação de nitrogênio e molibdênio na cultura do feijão de inverno: produção e qualidade fisiológica de sementes. Revista Brasileira de Sementes, Londrina-PR, v. 23, n. 1, p. 76-83, 2001.

BORTELS, H. Molybdän als Katalysator bei der biologischen Stickstoffbindung. Archives of Microbiology, Berlin, v. 1, p. 333-342, 1930.

BULEN, W. A.; LeCONTE, J. R. The nitrogenase system from Azotobacter: two enzyme requirements for N2 reduction, ATP-dependent H2 evolution, and ATPhydrolysis. National Academy of Sciences of the United States of America Proceedings, Washington, v. 56, p. 979- 986, 1966.

CASSINI; FRANCO. Fixação Biológica de Nitrogênio: microbiologia, fatores ambientais e genéticos. In: VIEIRA, C.; PAULA JUNIOR, T. J.; BORÉM, A. (Ed.). Feijão: aspectos gerais e cultura no Estado de Minas. Viçosa-MG: Universidade Federal de Viçosa, 2011. p. 143-170,

COELHO, F. C.; FREITAS, S. P.; MONERAT, P. H.; DORNELLES, M. S. Efeitos sobre a cultura do feijão das adubações com nitrogênio e molibdênio e do manejo das plantas daninhas. Revista Ceres, Viçosa-MG, v. 48, n. 278, p. 455-467, 2001.

CONAB. Campanha Nacional de Abastecimento. Indicadores da Agropecuária. Safras 2013/2014 - Grãos. Série Históricas: Feijão total (Safra 1, 2, 3 safras). Disponívelem:http://www.conab.gov.br/conabweb/download/s afra/FeijaoTotalSerieHist.xls. Acesso em: 1 de jul. de 2015.

DEPEC. DEPARTAMENTO DE PESQUISAS E ESTUDOS ECONÔMICOS. Feijão: junho de 2017. Disponível em: https://www.economiaemdia.com.br/EconomiaEmDia/pdf/infs et_feijao.pdf. Acesso em: 24 set. 2017.

EPSTEIN, E.; BLOOM, A. J. (Ed.) Nutrição mineral de plantas. Londrina-PR: Planta, 2006. p. 251-286.

FERREIRA, D. F. Sisvar: a computer statistical analysis system. Ciência e Agrotecnologia, Lavras-MG, v. 35, n. 6, p. 1039-1042, 2011. 
FERrEIRA, A. C. B.; ARAÚJO, G. A. A.; CARDOSO, A. A.; FONTES, P. C. R.; VIEIRA, C. Características agronômicas do feijoeiro em função do molibdênio contido na semente e da sua aplicação via foliar. Acta Scientiarum: Agronomy, Maringá-PR, v. 25, n. 1, p. 65-72, 2003.

GRIS, E.P.; CONTE, A. M.; OLIVEIRA, F. F. Produtividade da soja em resposta à aplicação de molibdênio e inoculação com bradyrhizobium japonicum. Revista Brasileira de Ciência do Solo, v.29, n.1, p.151- 155, 2005.

HUNGRIA, M.; CAMPO, R. J.; MENDES, I. C. A importância do processo de fixação biológica do nitrogênio para a cultura da soja: componente essencial para a competitividade do produto brasileiro. Londrina-PR: Embrapa Soja, 2007. 80 p. (Documentos, 283).

JESUS JÚNIOR, W. C.; VALE, F. X. R.; COELHO, R. R.; HAU, B.; ZAMBOLIM, L.; BERGER, R. D. Management of angular leaf spot in common bean (Phaseolus vulgaris L.) with molybdenum and fungicide. Agronomy Journal, Madison, v. 96, n. 3, p. 665-670, 2004.

KUBOTA, F. Y.; ANDRADE NETO, A. C.; ARAÚJO, A. P.; TEIXEIRA, M. G. Crescimento e acumulação de nitrogênio de plantas de feijoeiro originadas de sementes com alto teor de molibdênio. Revista Brasileira de Ciência do Solo, ViçosaMG, v. 32, p. 1635-1641, 2008.

MARCONDES, J. A.P.; CAIRES, E. F. Aplicação de molibdênio e cobalto na semente para cultivo da soja. Bragantia, Campinas-SP, v. 64, n. 4, p.687-694, 2005.

MARTENS, D. C.; WESTERMANN, D. T. Fertilizers applications for correcting micronutrient deficiencies. In: MORTVEDT, J. J.; COX, F. R.; SHUMAN, L. M.; WELCH, R. M. (Ed.). Fertilizers applications for correcting micronutrient deficiencies: micronutrients in agriculture. 2. ed. Madison: Soil Science Society of America, 1991. p. 549592.

MESCHEDE, D. K.; BRACCINI, A. L.; BRACCINI; M. C. L.; SCAPIM, C. A.; SCHUAB, S. R. P. Rendimento, teor de proteínas nas sementes e características agronômicas das plantas de soja em resposta à adubação foliar e ao tratamento das sementes com molibdênio e cobalto. Acta Scientiarum Agronomy, Maringá-PR, v. 26. n. 2, p.139-145, 2004.

OLIVEIRA, I. P.; ARAÚJO, R. S.; DUTRA, L. G. Nutrição mineral e fixação biológica do nitrogênio. In: ARAÚJO, R. S.; RAVA, C. A.; STONE, L. F.; ZIMMERMANN, M. J. O. (coords.). Cultura do feijoeiro comum no Brasil. PiracicabaSP: Potafós, 1996. p.169-216.

PESSOA, A. C. S.; RIBEIRO, A. C.; CHAGAS, J. M.; CASSINI, S. T. A. Atividades de nitrogenase e redutase de nitrato e produtividade do feijoeiro "Ouro Negro" em resposta à adubação foliar com molibdênio. Revista Brasileira de Ciência do Solo, v. 24, p. 217-224, 2001.

PESSOA, A. C. S.; RIBEIRO, A. C.; CHAGAS, J. M.; CASSINI, S. T. A. Concentração de foliar de Mo e exportação de nutrientes pelo feijoeiro "Ouro Negro" em resposta à adubação foliar com Mo. Revista Brasileira de Ciência do Solo, v. 24, n. 1, p. 75-84, 2000.
PERES, J. R. R.; SUHET, A. R.; MENDES, I. C.; VARGAS, M. A. T. Efeito da inoculação com rizóbio e da adubação nitrogenada em sete cultivares de feijão em solos de Cerrados. Revista Brasileira de Ciência do Solo, Campinas-SP, v. 18, n.3, p. 415-420, 1994.

SANTOS, A. B.; SILVA, O. F. Manejo do nitrogênio. In: AIDAR, H.; KLUTHCOUSKI, J.; STONE, L. F. (Ed.). Produção do feijoeiro comum em várzeas tropicais. Santo Antônio de Goiás-GO: Embrapa Arroz e Feijão, 2003. p. 207216.

SILVA, E. F.; MARCHETTI, M. E.; SOUZA, L. C. F.; MERCANTE, F. M.; RODRIGUES, E. T.; VITORINO, A.C.T. Inoculação de feijoeiro com Rhizobium tropici associada a exsudato de Minosa floculosa com diferentes doses de nitrogênio. Bragantia, Campinas-SP, v. 68, n. 2, p. $443-451,2009 b$

SILVA, F. C. Manual de análises químicas de solos, plantas e fertilizantes. 2. ed. Brasília-DF: Embrapa Informações Tecnológicas, 2009a, 627 p.

SOUZA, R. A.; HUNGRIA, M; FRANCHINI, J. C.; CHUEIRE, L. M. O.; BARCELLOS, F. G.; CAMPO, R. J. Conjunto mínimo de parâmetros para avaliação da microbiota do solo e da fixação biológica do nitrogênio pela soja. Pesquisa Agropecuária Brasileira, Brasília-DF, v. 43, n. 01, p. 83-91, 2008.

SOUZA, E. F. C.; SORATTO, R. P.; PAGANI, F. A. Aplicação de nitrogênio e inoculação com rizóbio em feijoeiro cultivado após milho consorciado com braquiária. Pesquisa Agropecuária Brasileira, Brasília-DF, v. 46, n. 4, p. 370-377, 2011.

SORATTO, R. P.; CARVALHO, M. A. C.; ARF, O Nitrogênio em cobertura no feijoeiro cultivado em plantio direto. Revista Brasileira de Ciência do Solo, Viçosa-MG, v. 30 , n. 2, p. 259-265, 2006.

TORRES, H. R. M.; RIBEIRO, P. R. C. C.; RIBEIRO, J. J.; produtividade do feijão phaseolus vulgaris 1 . com aplicações crescentes de molibdênio associadas ao cobalto via foliar. Enciclopédia Biosfera, Goiânia-GO, v.10, n.18; p.2468-2481, 2014

VIEIRA, C. Adubação mineral e calagem. In: VIEIRA, C.; PAULA JUNIOR, T. J.; BORÉM, A. (Ed.). Feijão: aspectos gerais e cultura no Estado de Minas. Viçosa, MG: Universidade Federal de Viçosa, 2006. p. 123-152.

XAVIER, T. F.; ARAÚJO, A. S. F.; SANTOS, V. B.; CAMPOS, F. L. Influência da inoculação e adubação nitrogenada sobre a nodulação e produtividade de grãos de feijão-caupi. Ciência Rural, Santa Maria-RS, v. 38, n. 7, p. $25-32,2008$ 